\title{
An interactional analysis of one-to-one pastoral care delivery within a primary school
}

\section{Louise Bradley \& Carly W. Butler}

To cite this article: Louise Bradley \& Carly W. Butler (2016): An interactional analysis of one-to-one pastoral care delivery within a primary school, Pastoral Care in Education, DOI: 10.1080/02643944.2016.1243145

To link to this article: http://dx.doi.org/10.1080/02643944.2016.1243145

Published online: 20 Oct 2016.

Submit your article to this journal $\sqsubset$

Q View related articles $\square$

View Crossmark data \lceil 


\title{
An interactional analysis of one-to-one pastoral care delivery within a primary school
}

\author{
Louise Bradleya (i) and Carly W. Butler ${ }^{b}$ \\ aFaculty of Health and Life Sciences, Centre for Research in Psychology, Behaviour and Achievement, Coventry \\ University, Coventry, UK; ${ }^{b}$ Department of Social Sciences, Loughborough University, Loughborough, UK
}

\begin{abstract}
Despite an interactional analysis being able to offer valuable insight into the institutional workings of pastoral care practice, pastoral care delivery remains largely unstudied. This paper will contribute new knowledge to the field of counselling and education by offering an interactional analysis of one-to-one pastoral care provision within a primary school. Much pastoral care practice is informed by theory, often accompanied by guidelines about how to deliver pastoral care activities effectively. The pastoral carer needs to convert these guidelines into talk in order to deliver the intervention as an interactional encounter. However useful these guidelines are, they cannot show what the actual delivery of those pastoral care activities might look like in real life. Using conversation analysis, we examine video recordings of pastoral care delivery to reveal the ways in which a pastoral carer supports a child's behaviour, social and emotional well-being. The significance of the findings is that those who provide pastoral care can see in close detail what delivery might look like as a real-life encounter, imparting valuable knowledge that can then be applied alongside theory and guidelines to enhance professional practice. Of further significance is that the findings can also show how an interactional analysis of pastoral care work can be used to demonstrate social and emotional learning and that the work being done effectively supports children.
\end{abstract}

\section{ARTICLE HISTORY}

Received 10 August 2016

Accepted 30 August 2016

\section{KEYWORDS}

Children's interactions; conversation analysis; pastoral care; primary school; social, emotional and behavioural difficulties

\section{Introduction}

Pastoral care is a school-based intervention that falls under the umbrella concept of 'guidance and counselling', delivered to children individually, in groups or as a whole school approach. Although both'pastoral' and 'care' are difficult concepts to define (see Calvert, 2009), in their classic paper, Best, Jarvis, and Ribbins (1977) define it quite simply as 'the form guidance and counselling takes when it is provided by school teachers within a particular institutional setting' (p. 126). Although teachers have typically delivered pastoral care in the past, more recently it has become common practice to share provision with support staff (Davies, 2010). This move has been encouraged because pastoral care predominately relates to notions of 'care', and so a teaching background is no longer deemed necessary (Davies, 2010). In 
practice, those providing pastoral care consider their'caring' role to be bound to both actual pastoral care practices and the way in which those practices are performed (Best, 2000). As such, 'pastoral' and 'care' become practical activities that are interactionally achieved, rather than concepts that are often invisible and taken for granted (see Eldén, 2012). Therefore, an interactional analysis can provide valuable insight into both what and how pastoral care activities are performed and delivered.

Pastoral carers, like many counsellors and therapists, may often be unaware of the range, or detail, of the interactional skills they use to deliver their practice. However, the skills needed to deliver successful intervention, such as the ability to build rapport and gain trust, are not invisible unknown practices because effective practitioners use them all the time (Seligman, 2002). Yet, research rarely studies these practices in action because many methods are unable to study interaction empirically or robustly. An interactional analysis, however, allows for such examination. The primary method used to study interaction is conversation analysis (CA), a well-developed tradition that has a distinct methodological and analytic procedure that is supported by a large body of research findings (Sidnell, 2013). Conversation analysts explore what is 'actually done in the therapeutic interview' (Labov \& Fanshel, 1977, p. 3), to identify the practices being used to accomplish the interactional aims. In a study by Fogarty, Augoustinos, and Kettler (2013), CA was used to analyse investigative interviews with children about alleged sexual abuse. It was found that during disclosure rapport was maintained through the use of drawings. Drawings lessened the intensity of eye-gaze during these traumatic tellings by giving the interactants a legitimate reason not to engage in eye contact, as they provided a third object of focus to sensitively manage the interaction. Similarly, Butler, Danby, and Emmison (2011) used CA to analyse helpline telephone calls. They found that when counsellors took an opposing stance to the child they were counselling they would use the child's name to manage rapport and maintain the counselling relationship. Findings from such studies offer valuable insight into the ways practitioners actively manage moments of discomfort during delivery to accomplish their interactional aims. Using the same method, this paper will analyse an example of pastoral care provision to examine how pastoral care is delivered to support a child's behaviour, social and emotional well-being.

\section{Data and analytic method}

The data and analysis presented here come from my $\mathrm{PhD}$ research that used $\mathrm{CA}$ to look at how adults support children make sense of the troubles in their lives. When using CA, there is a preference for analysts to collect interactions that are naturally occurring, that is interactions that take place regardless of researcher involvement (see Potter, 2002). In order to capture these interactions fully it is common practice to video record. The data, then, are video recordings of one-to-one sessions between a pastoral carer and child within a primary school, who I contacted through an associate to help me gain access.

The pastoral carer, who the children called 'Miss', looked after the social and emotional needs of the children at the school. Her role was quite different to that of a teaching assistant as she was not based in the classroom, but in a separate office, and the support she offered was emotional rather than educational. Miss chooses to record her sessions with 'Morgan' (his pseudonym). At the time of recording Morgan was in Year 4, so aged between eight and nine years old. His teachers identified him as needing regular pastoral care because of 
friendship troubles. However, as time went on it became clear that he also needed support because of difficulties being experienced at home. Miss spoke to Morgan and his father about the research and obtained their consent.

The data-set consisted of six sessions (approximately $3.5 \mathrm{~h}$ in total) that were video-recorded over three weeks. I was not present during these sessions but would set up two video recorders in Miss's office before each session began, and collect them after each session finished when Morgan had returned to his classroom. To cause the least disruption for Morgan, Miss would begin recording before she left her office, so that when they arrived back their time together would be as usual as possible. Likewise at the end of their session, Miss would take Morgan to his classroom and then stop the recording when she arrived back in her office. The recorders were visible at all times so Morgan was aware that they were there, and on occasion spoke about them to Miss who explained they were for the research project. Morgan was also aware that he could stop recording at any time.

The recordings were transcribed and analysed using conversation analysis (see Sidnell, 2010 for an introduction to CA). CA is an inductive method of analysis so the analyst does not approach the data hoping to find specific themes, but instead allows these to emerge from the data through the process of analysis. A core feature of CA is that talk is action-oriented and used to do things within interaction. Analysis involves examining sequences of talk to see how turns are constructed, what a turn is being used to do, and how the next speaker responds. When using CA, any analytic claims must be grounded in the data rather than imposed by the analyst. In other words, claims must be guided and shaped by what is observable and visible in the data. This is why conversation analysts stress the importance of working with real-life recorded interactions because they allow the analyst to study the interaction as it unfolds to see what actually happens. The analyst does not draw on their own assumptions to explain what is happening in any interaction, but looks to see what evidence there is of the participant's own assumptions and understandings in the data. The analytic procedure involves producing transcripts that include details of how people talk to each other. For example, emphasis placed on words, stretching the sound of some letters, silences within or between turns to show when talk begins and ends, are all noted within the transcript. As are non-verbal gestures such as a head nod, eye gaze or facial expression, as analysts treat all aspects of interaction as relevant and needed to fully understand what is being communicated and responded to (see the Appendix 1 for transcription notations, based on Jefferson, 2004).

A collection of extracts was gathered to look at how therapeutic tools and practices were being used within the pastoral care interactions to support Morgan's behaviour, social and emotional well-being. By using a conversation analytic approach, we are able to show that pastoral care practice is as much about the interactional ways in which a pastoral carer packages and delivers her intervention, as it is about the tools and practices she uses. It is in this sense, then, that pastoral care is indeed, as Best (2000) describes, bound to both actual pastoral care practices and the way in which those practices are performed.

\section{Pastoral care practices}

This paper will look at how two therapeutic tools, the 'worry box' and 'traffic light system', were identified as being used in Miss's pastoral care work to support Morgan's behaviour, 
social and emotional well-being. As will be seen, the use of these tools is examined to show how they are delivered within the caring environment that is bound to pastoral practice, and that the ways in which they are used within these interactions enable the pastoral work to be done. The use of these tools will also be examined to show how they support a child's agency and participation in practice. By agency we refer to Morgan's ability to determine the interactional course of action, and by participation we refer to Morgan's ability to engage in the pastoral care work being done.

\section{The 'worry box'}

The worry box is quite simply a box for Morgan to store his worries, and it is a regular feature in Morgan and Miss's sessions. It is made from an empty A4 printer paper box that Morgan has colourfully decorated with tissue paper and paint. As a therapeutic tool, the worry box allows Morgan to recognise, express, share and contain his worries with the help and support of Miss. When a worry arises, Morgan writes it on a piece of paper, reads it out to Miss for discussion, and then places it into his worry box for safekeeping where it remains available for discussion if and when he wishes. The box is available in every session and can be made relevant within the interaction by Morgan or Miss at any time, without being interruptive or in need of explanation. This can be seen in the following extract (see Appendix 1 for transcription notations) when Morgan announces he has a worry while silently cutting out a drawing he has done of his sister.

(1)

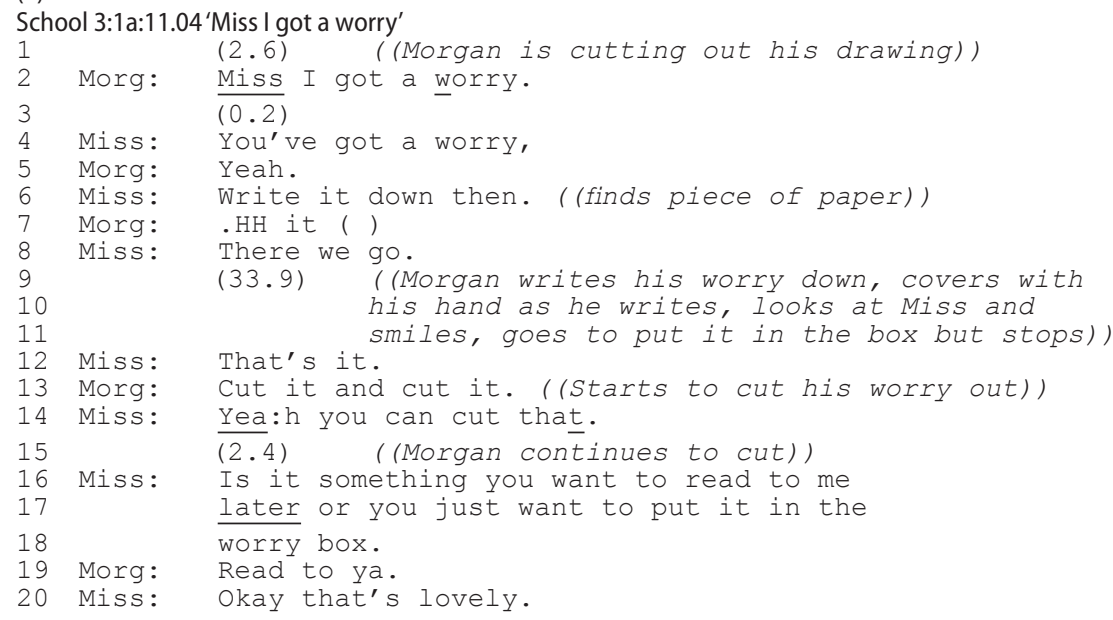

The extract shows how Morgan's agency and participation are supported through the collaborative nature of the interaction. The sessions are not rigidly structured or lead by Miss (although she organises an activity to begin each session) but flexible enough to include whatever is happening in Morgan's life. Morgan makes his worry interactionally relevant by announcing, 'Miss I got a worry' (line 2). Miss finds Morgan some paper and tells him to write his worry down. As Morgan writes he can be seen placing his hand in front of the paper so Miss cannot read it, looking up now and then as he writes to check Miss is not looking. Miss keeps her eyes averted. Morgan's actions appear light-hearted, as he can be seen smiling in the recording, showing a positive, relaxed, playful side to their relationship. Morgan goes to 
place his worry in the box, which Miss encourages with 'that's it' (line 12), but instead he retracts and starts to cut the paper out around the worry to make it smaller, which he explains on line 13. Miss continues to support Morgan's agency by asking him if he would like to read his worry to her later or if he just wants to put it into the box, presumably because of Morgan's playful attempts to hide it from her while he wrote it down.

The worry box allows Morgan to suddenly announce he has a worry without it being a major event, and it seems this might not be possible without such a tool. The worry box also allows Morgan to decide how he shares his worries because the box allows him to manage how much time and attention his worries are given. As the extract shows, it is Morgan who decides when, and how, to express and share his worry with Miss, and the way in which this is done. Morgan is displaying agency through the way he is able to select, construct and regulate the telling of his worry. It is Morgan who controls the interactional course of action, which Miss supports throughout.

Morgan uses the box to keep safe two different types of worries. The first are his 'big' worries that are constant and cannot be fixed by Morgan or Miss:'I want my mummy to live with me'. The second are more transient, fixable worries that arise within his everyday life: 'Bradley was hitting my worry box.' The worry box serves two functions then, to keep safe the constant worries in Morgan's life, and contain his everyday worries until they are no longer troubling him. In the following extract Miss initiates a review of Morgan's worries.

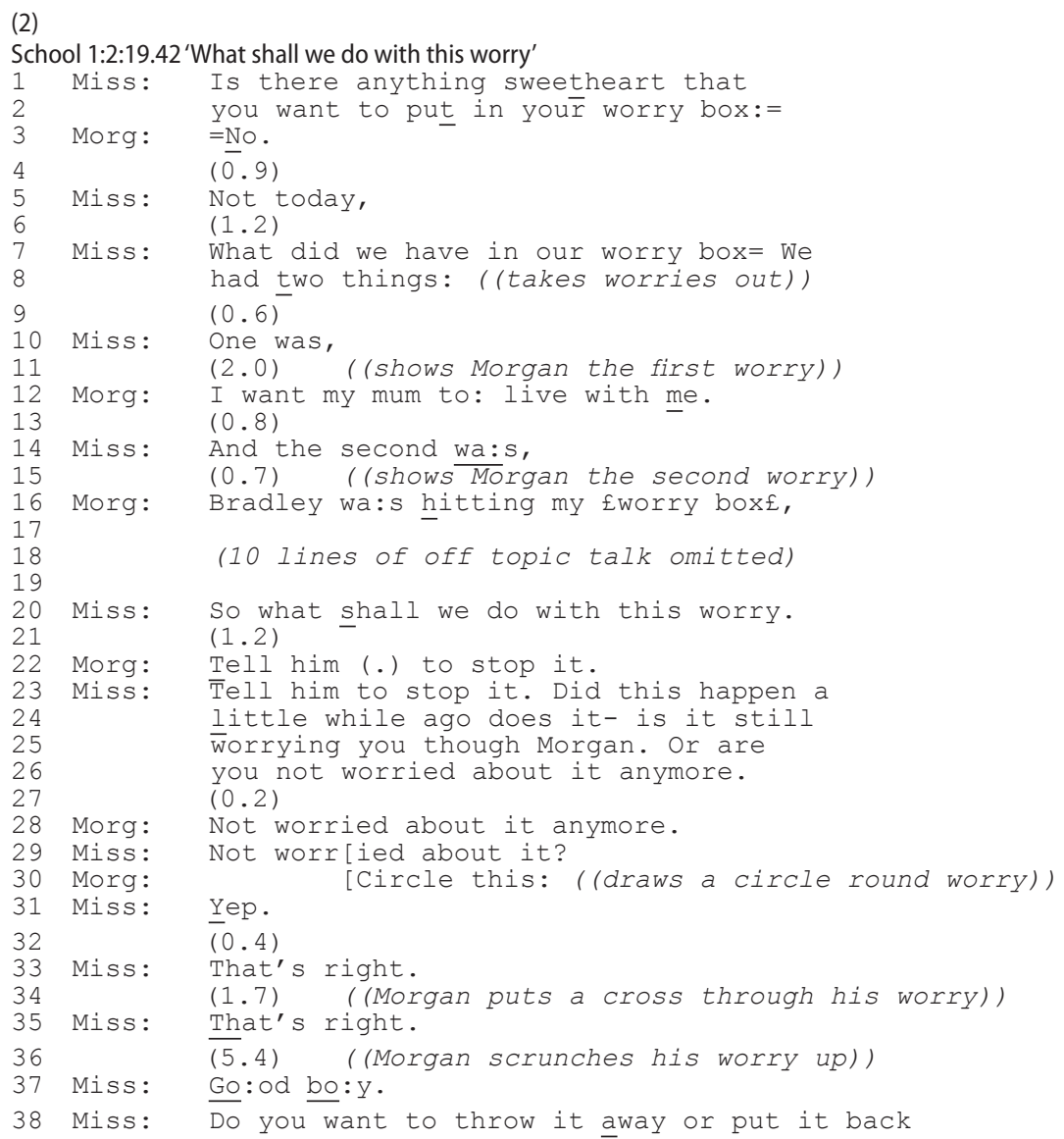




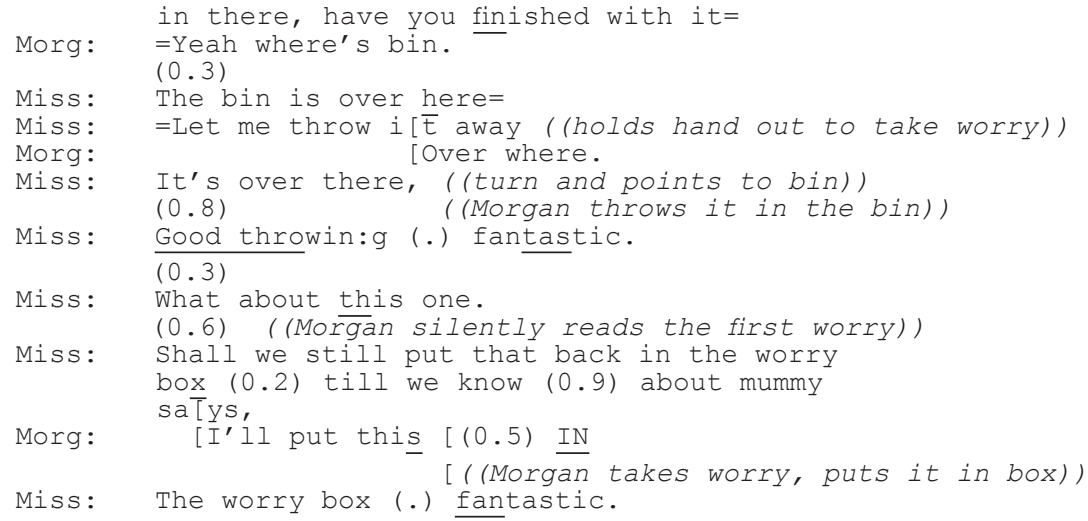

Following her enquiry, Morgan informs Miss that he doesn't have anything to put in the box today (line 3). Miss then initiates a review of the worries already in his box (line 7-8) using the collective references 'we' and 'our' to display togetherness (Bradley \& Butler, 2015). Miss holds up the first worry and Morgan reads it out, 'I want my mum to live with me' (line 12), and then the second, 'Bradley was hitting my worry box' (line 16). Miss asks Morgan what they should do with his second worry (line 20) and Morgan offers a way to fix the problem, 'tell him to stop it' (line 22). It is agreed that this incident happened a while ago and that it is no longer a worry for Morgan, so he draws a circle around it, puts a cross through it and writes something over it before scrunching it up.

There is something quite therapeutic and liberating about the way the worry box helps Morgan deal with his worries. In the case of Bradley hitting his box, the worry is treated objectively, writing it down on a piece of paper externalises his emotions about this troubling situation. His subsequent act of discarding the worry, the highlighting (circling), erasing (crossing out and writing on it) and dismissal of it (scrunching it up), enacts that he is now free of it. He has taken charge of what might seem like a minor transgression to some, but for Morgan who started to see Miss because of his angry ways of dealing with friendship troubles this is a great achievement. Miss recognises this and encourages his actions, 'yep that's right' (lines 31-33), enthusiastically praising him 'Go:od bo:y' (line 37). She then asks Morgan if he wants to throw the worry away or put it back into the box (lines 38-39).

Morgan confirms he wants to throw it away with, 'Yeah where's bin' (line 40). He rejects Miss's offer to throw it away for him by asking her again where the bin is. This shows how Morgan's agency is supported once more. As an active participant Morgan can determine the interactional course of action. It again shows the relaxed, playful atmosphere that has been collaboratively formed, as Morgan throws the paper across the room into the bin. This would seem inappropriate in the more formal setting of a classroom where control is actively managed by the teacher to keep order. Here, Morgan is much freer and 'agentic' in his relationship with Miss. He throws his worry in the bin and Miss congratulates him, 'Good throwin:g (.) fantastic' (line 47), to endorse his playful act.

Miss then asks Morgan about his other worry, 'I want mum to live with me', and while he reads it to himself Miss suggests he put it back into the box until they hear what mum has to say (lines 51-53). This refers to an earlier part of the session when Morgan wrote his mum a letter to tell her that he wanted her to come home. Despite Miss suggesting what Morgan might do, Morgan takes control once more by taking the worry from Miss assertively 
announcing, 'I'll put this IN' (lines 54). Morgan's response is more than an agreement of Miss's suggestion, the 'I'll' takes control to verify this is a personal course of action. Miss continues to support and collaborate these moves by completing his turn (see Lerner, 2004) with, 'the worry box', before praising him once more, 'fantastic' (line 56), for his actions.

The two extracts so far have shown that the worry box is a tool that helps Morgan recognise, express, share and contain his worries, which is a valuable resource in itself. However, by looking at the ways in which the worry box has been used within the interaction not only have the theoretical underpinnings of this tool been explored, a number of other affordances have been identified. Morgan playfully and positively discussed and managed his worries within a caring environment that is bound to pastoral practice, and in so doing further enhances that caring environment to facilitate the pastoral work being done. The way Miss packaged her questions as suggestions (for example, 'shall we put that back in the worry box'), allowed Morgan to take charge of the interactional course of action, showing how his agency and participation were supported in practice. Through supporting Morgan's agency and participation Miss encouraged him to make his own decisions, so Morgan could display his own expertise and ability to deal with his worries. It is through examining how the worry box is used within interaction that this tool is seen to accomplish so much more than just be a safe place for Morgan to store his troubles.

\section{The 'traffic light system'}

The traffic light system is another tool used by Miss to help Morgan manage his friendship troubles. In the same way that the worry box was examined, the following discussion will show the interactional affordances of the traffic light system - how it is delivered within a caring environment bound to pastoral practice to further enhance that caring environment and facilitate the therapeutic work being done, how it supports Morgan's agency and participation in practice, and how it supports Morgan's behaviour, social and emotional well-being. Miss introduced the system when Morgan was first referred to her as a way of monitoring how he is feeling when troubles arise, so he can manage his emotions and behaviour to prevent him from having angry outbursts and getting into trouble. The system is a narrative that provides Morgan (and other children) a scripted description of actions in three steps: green, orange and red. Each colour is linked to an assessment that describes different stages of emotion, along with socially appropriate behaviours and actions. The following two extracts come from discussions that explain when, why and how the system should be used. In the extract below, Miss shows Morgan the traffic light image and he recites, 'green means carry it on, orange is be careful, and the red is stop it and walk away'.

(3)

School 1:4.13 'The traffic light system'

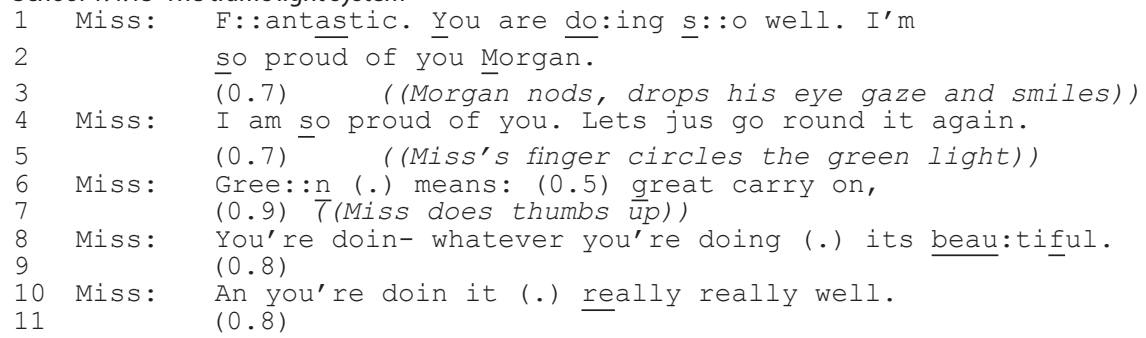




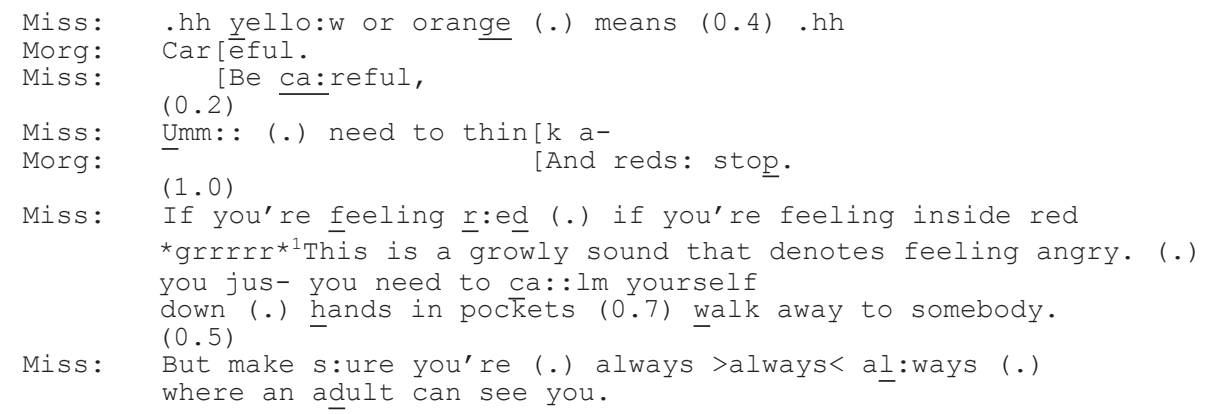

Miss assesses Morgan's recital, 'fantastic' (line 1), before praising him and telling him how proud she is (lines 1-2). The enthusiasm in her voice can be seen in the transcript and Morgan responds non-verbally with his head nod, dropped eye gaze and smile (line 3), to acknowledge Miss's assessment and display his emotional response.

Miss then proposes they go over it again, using positive affirmations to describe Morgan's pro-social behaviours, 'great' (line 6), 'beautiful' (line 8), 'really really well' (line 10). Miss provides a more extensive narrative for when Morgan is 'feeling inside red' (lines 19-24) to describe what he should do when he starts to feel angry. It is this stage in the system that specifically modifies Morgan's behaviour to prevent it from being problematic. Therefore, if Morgan follows the system as a scripted narrative he can begin to recognise, monitor and control his emotions and behaviour by developing his self-awareness, self-control and 'what to do' knowledge. These developments are essential because as children grow they are increasingly held responsible for their own behaviour (Mowat, 2012). So, children need to develop their social skills, and tools like the traffic light system promote such development.

Morgan's knowledge and understanding about how the system will help him is what will enable him to use this tool as a real-life method, to regulate his emotions when difficult situations occur so he can improve his behaviour and friendships. In the following extract, Miss tests Morgan's knowledge and understanding.

(4)

School 2:8.00 'How is it working for you'

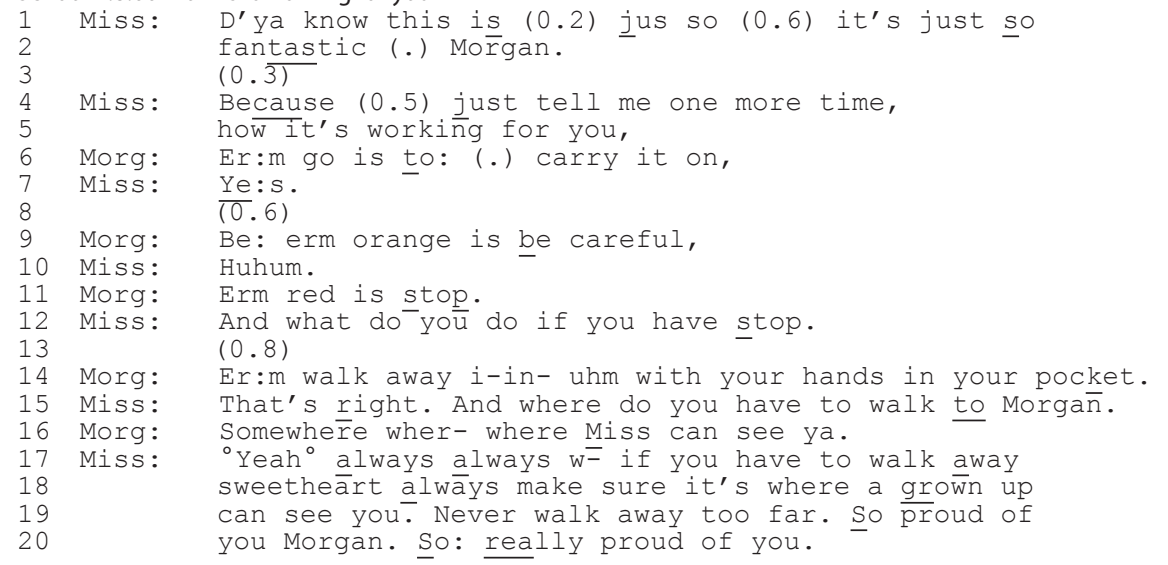

Miss introduces the discussion with a positive assessment asking Morgan to tell her how the system is working for him (line 1-5). Morgan explains the green and orange colours and 
their associated behaviours (line 6 and 9), which Miss affirms (line 7 and 10) to encourage his answers and display attentiveness. Miss then asks Morgan what he would do if he has to 'stop' (line 12) and 'where do you walk to' (line 15), as this is where the system helps him control his angry outbursts. With each prompting question, Miss invites Morgan to explain what he should do. These collaborative turns allow him to display his knowledge and understanding, and show that he understands how he can better manage his anger and behaviour.

The theory behind the system seems to be that by developing self-awareness Morgan will in turn be able to self-regulate. However, without agency and motivation these goals are not possible as it is not enough to simply tell a child how to behave. The interaction shows that Morgan can display his understanding of the system, so as a conceptual lesson the teaching that has taken place can be seen as successful. Yet, understanding a concept does not mean that a child will transfer newly learnt skills from a controlled environment to a real-life scenario when it is actually needed to manage strong emotions being experienced.

With this in mind, the next extract shows how Morgan tells Miss how he has used the system outside of their sessions to manage real-life conflict. In the following interaction, Morgan and Miss are looking at expression cards to talk about his feelings. Morgan selects the 'angry' card to describe a situation that occurred between him and a peer in school. Miss treats Morgan's telling as an example of how he has transferred his knowledge of the traffic light system into a real-life method to control his anger.

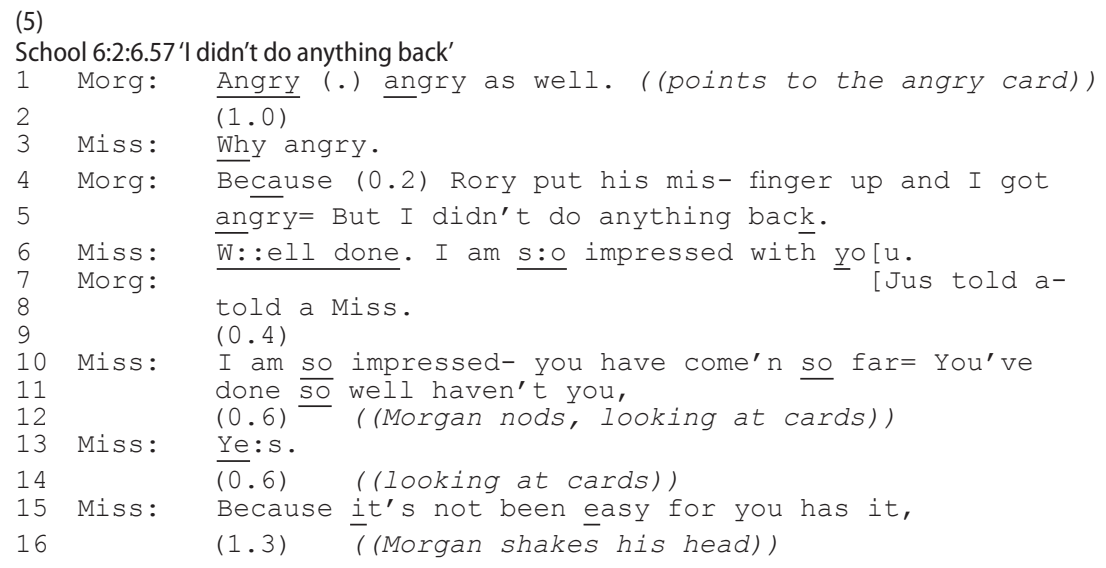

Morgan chooses the 'angry' card and when asked 'why angry' he recites a time when another boy cursed him and he did not retaliate (lines 4-5). Miss praises Morgan's actions in her tribute and Morgan adds, 'jus told a- told a Miss' (lines 7-8) to explain what he did do to manage the situation. Miss recognises that Morgan not doing 'anything back' is an achievement in contrast to his previous behaviours, and why the traffic light system was introduced to help him manage his anger. Morgan himself has been in charge of this change. He decided not to do 'anything back', despite feeling angry, instead he 'just told a Miss'. Morgan's telling displays how his self-awareness and self-control have developed to help him know what to do when facing difficulties with his peers. Miss repeats once more how impressed she is with him, the changes he has made, and the effort this has taken (lines 10-15). 
The extract shows how Morgan practiced a new way of dealing with friendship troubles, communicated this to Miss and received positive feedback. This demonstrates that outside of the time Morgan spends with Miss, he can effectively control and manage his emotions and behaviour to deal with real-life conflict. However, it was not just the system that allowed Morgan to do this, it was the way in which the system was packaged and delivered by Miss. The teachings were positive and solution-focused and Miss took the time to ensure Morgan understood how and why the system would help him regulate his emotions and behaviour. The final extract shows how Miss promotes Morgan's choices by the comments of others in the school to further reinforce his pro-social behaviour.

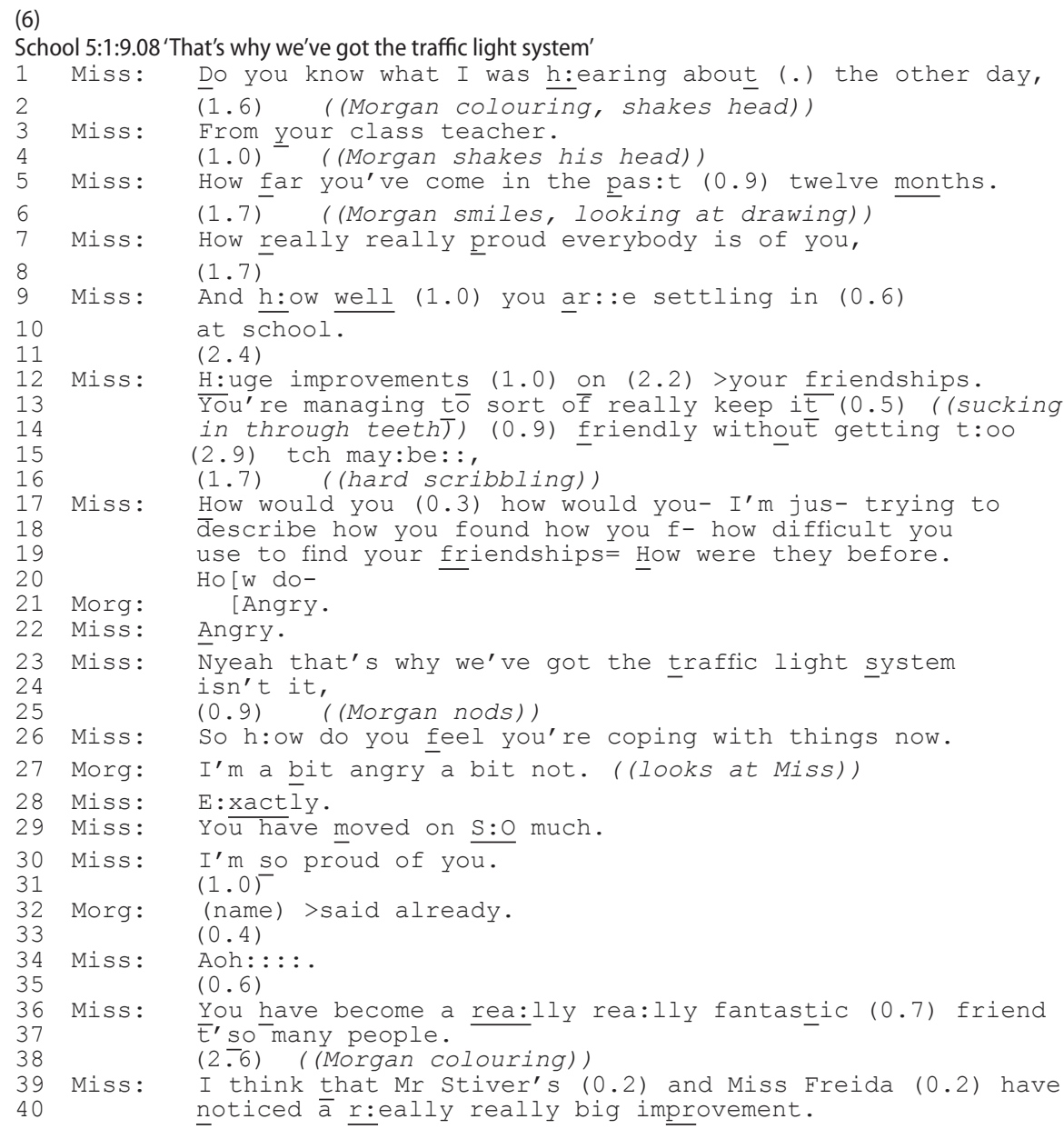

Miss tells Morgan how his teachers have reported the progress he has made in the last 12 months to improve his friendships in school. The talk is widening the extent of Morgan's progress by reporting how others have noticed a change in his behaviour, and this reporting works to maximise and reinforce the changes that Morgan has made. Miss asks Morgan to describe his friendships before the system (lines 17-20) and he responds 'angry' (line 22). By questioning and inviting Morgan's version of events his agency and participation are supported in practice. Miss does not assume to know more about Morgan's life than him, rather 
she positions Morgan as having the authority to describe his friendships and confirm (head nod on line 25) this is why they have the traffic light system.

Miss then asks Morgan to evaluate the changes in his friendships and he responds, 'I'm a bit angry a bit not' (line 28), and in so doing displays his ability to form his own meaningful evaluation. Miss marks this change as something she can also assess and confirm, 'E:xactly' (line 29), before praising Morgan highly, 'You have moved on S:O much I'm so proud of you' (line 29-31), to reveal her own, and Morgan's teacher's, evaluation of his change (line 37-40). The sequencing of these evaluations with Morgan being positioned first continues the work being done by Miss within the interaction to support Morgan's agency and participation.

The traffic light system is a tool that allows Morgan and Miss to engage in pastoral care work. However, it is the way in which it is packaged and delivered (for example via invitations to do self-assessment - lines 17-24) that Morgan can both verbalise and hear how well he is doing in changing the way he manages his friendships. The extract then shows how Miss explicitly constructs a positive version of Morgan's self within the interaction, 'you have become a rea:lly rea:Ily fantastic friend t'so many people' (line 36-37). By internalising this positive assessment that has been revealed by Miss, the teachers, and Morgan himself, 'bit angry a bit not' (line 27), Miss offers Morgan a positive self description to support his behaviour, social and emotional well-being.

\section{Conclusion}

The aim of this paper was to use an interactional analysis to look at an example of pastoral care provision, to reveal the ways in which a pastoral carer supported a child's behaviour, social and emotional well-being. The delivery of the worry box and traffic light system were examined to reveal the interactional and therapeutic affordances of these two tools. The analysis showed that the worry box supported Morgan to talk about his emotions and feelings in order to help him make sense of the difficulties he was experiencing; while the traffic light system gave Morgan the skills and knowledge he needed to manage, change and overcome his difficulties. Furthermore, the worry box and traffic light system were found to support Morgan's agency and participation, for example, the way Morgan chose to use the worry box and share his worries, and the way Morgan put into action the traffic light system to resolve real-life conflict.

There is an increasing need for both researchers and professionals to show that the work they do is effective in supporting children, yet being able to demonstrate support and its outcomes can be difficult. This paper has demonstrated that CA is a method that effectively allows us to look at how the pastoral care work being done is packaged, delivered and responded to. Therefore, we can support what has previously been theorised, that the therapeutic power of pastoral care is indeed bound as much to the interactional ways in which activities are delivered, as it is to the activities themselves. Furthermore, CA allows us to capture real-life moments of social and emotional learning, to show that the pastoral care work being done effectively supports a child's well-being. The significance being that pastoral carers can increase their awareness of the ways in which their work is effective to inform their professional practice. 


\section{Acknowledgements}

We would like to gratefully acknowledge the primary school, and in particular, Morgan and Miss for their participation. This paper derived from the corresponding authors PhD study that was funded by The Graduate School at Loughborough University Graduate School, Loughborough University, UK.

\section{Disclosure statement}

No potential conflict of interest was reported by the authors.

\section{ORCID}

Louise Bradley (iD http://orcid.org/0000-0003-4136-8816

\section{References}

Best, R. E. (2000). Concepts in pastoral care and PSE. In R. Best, P. Lang, C. Lodge, \& C. Watkins (Eds.), Pastoral care and personal-social education: Entitlement and provision (pp. 3-18). London: Continuum.

Best, R. E., Jarvis, G. B., \& Ribbins, P. M. (1977). Pastoral care: Concept and process. British Journal of Educational Studies, 25, 124-135.

Bradley, L., \& Butler, C. W. (2015). Managing and normalising emotions and behaviour: A conversation analytic study of ADHD coaching. In J. N. Lester \& M. O'Reilly (Eds.), The Palgrave Handbook of Child Mental Health (pp. 480-499). Basingstoke: Palgrave Macmillan.

Butler, C. W., Danby, S., \& Emmison, M. (2011). Address terms in turn beginnings: Managing disalignment and disaffiliation in telephone counselling. Research on Language and Social Interaction, 44, 338-358.

Calvert, M. (2009). From 'pastoral care'to 'care': Meanings and practices. Pastoral Care in Education, 27, 267-277.

Davies, S. (2010). Support staff undertaking pastoral roles: Perceptions within the school settings (Unpublished PhD thesis). University of Bristol.

Eldén, S. (2012). Inviting the messy: Drawing methods and 'children's voices'. Childhood, 1-16.

Fogarty, K., Augoustinos, M., \& Kettler, L. (2013). Re-thinking rapport through the lens of progressivity in investigative interviews into child sexual abuse. Discourse Studies, 15, 395-420.

Jefferson, Gail (2004). Glossary of transcript symbols with an introduction. In G. H. Lerner (Ed.), Conversation analysis: Studies from the first generation (pp. 13-31). Philadelphia, PA: John Benjamins.

Labov, W., \& Fanshel, D. (1977). Therapeutic discourse: Psychotherapy as conversation. New York, NY: Academic Press.

Lerner, G. H. (2004). Collaborative turn sequences. Pragmatics and Beyond New Series, 125, 225-256.

Mowat, J. (2012). 'It wasnae (only) $\mathrm{me}^{\prime}$ - The development of self-regulation and self-responsibility in pupils experiencing social and emotional behavioural difficulties. In J. Visser, H. Daniels, \& T. Cole (Eds.), Transforming troubled lives: Strategies and interventions for children with social, emotional and behavioural difficulties (pp. 251-272). Bingley: Emerald Group Publishing.

Potter, J. (2002). Two kinds of natural. Discourse Studies, 4, 539-542.

Seligman, M. E. P. (2002). Positive psychology, positive prevention, and positive therapy. In C. R. Snyder \& S. J. Lopez (Eds.), Handbook of positive psychology (pp. 3-9). New York, NY: Oxford University Press.

Sidnell, J. (2010). Conversation analysis: An introduction. West Sussex: Wiley-Blackwell.

Sidnell, J. (2013). Basic conversation analytic methods. In J. Sidnell \& T. Stivers (Eds.), The handbook of conversation analysis (pp. 77-100). West Sussex: Wiley. 


\section{Appendix 1}

Transcription conventions (adapted from Jefferson, 2004).

$(0.2)$

(.)

:

Wor-

Word

word

WORD

£word $£$

-

,

?

$>$ word $<$

[]

$=$

.hh

((head nod))

( )
Timed silence

A micro-pause, less than 0.2 seconds

Preceding sound is stretched

A dash represents a cut-off before completion

Underlining shows stress or emphasis

Degree signs show the word is quieter than surrounding talk

Capitalisation shows increased volume

Word spoken with a smile

A full stop represents a falling, final intonation

Comma shows a slightly rising, continuing intonation

Shows a rising, questioning intonation

Rushed speech

Square brackets represent overlapping talk

Speech that is latched onto the prior turn without a beat of silence

In-breath

Description of non-verbal actions

Inaudible talk is represented by empty brackets 